\title{
The External Effects of Black-Male Incarceration on Black Females
}

\author{
Stéphane Mechoulan* \\ University of Toronto
}

2006

\begin{abstract}
I examine how the increase in the incarceration of Black men and the sex ratio imbalance it induces shape young Black women's behavior. Combining data from the BJS and the CPS to match incarceration rates with individual observations, I show that Black-male incarceration lowers the odds of non-marital teenage fertility and increases single Black women's school attainment and early employment, while decreasing White women's labor-force participation. I do not find consistent evidence that high Black-male incarceration rates decrease the likelihood of marriage for young Black women. These results are robust to using sentencing changes and prison capacity expansions as instruments for incarceration.
\end{abstract}

JEL Classification: I21, J12, J13, J15, J22, J24, K42

* I am indebted to seminar participants at the University of Toronto, the $16^{\text {th }}$ meeting of the American Law and Economics Association, as well as Abhijit Banerjee, Gadi Barlevy, David Bjerk, Josh Fischman, Shoshana Grossbard, Marc Mauer, Abigail Payne, William Sabol for helpful conversation and comments; Paige Harrison and Janice Munsterman from the U.S. federal Department of Justice and numerous State Department of Corrections officials for their help in accessing and making sense of the data; Kevin Reitz, Fred Cheesman, Michael Tonry, Mark Cohen, Rachel Barkow, Patricia Cluney, Eric Sterling, Judi Greene, Peggy Rogers, Shawn Bushway, for guidance in better understanding the U.S. criminal justice system and for their encouragement throughout this arduous task. Special thanks to Emefa Sewordor and all the undergraduate students enrolled under the University of Toronto Research Opportunity Program who worked on this project for their input. All errors are my own. Contact: s.mechoulan@utoronto.ca 


\section{Introduction}

The United States has experienced a dramatic surge in imprisonment over the last three decades that has specifically affected the Black community. Overall, Blacks are now incarcerated at nine times the rate of non-Hispanic Whites and comprise more than $40 \%$ of inmates. One in eight Black males age 25-29 was behind bars in 2004. ${ }^{1}$ Given current trends, one Black male child out of three will go to prison or jail at some point in his lifetime.

High male-incarceration rates wreak havoc on the social structure of the Black community. ${ }^{2}$ In particular, as the prevalence of imprisonment is more than fifteen times higher for Black men than for Black women, Black women face a momentously unfavorable sex ratio. ${ }^{3}$ Yet the collateral, unintended effect of Black-male incarceration on single Black females' socioeconomic outcomes is largely unexplored. The analysis of Black women’s choices when facing a shock in the supply of men provides an original test of the standard model of market behavior in family economics. Moreover, once quantified, the effect of incarceration may be fruitfully contrasted with the effects of explicit policies designed to improve those same outcomes.

\footnotetext{
${ }^{1}$ Source: Bureau of Justice Statistics Prison and Jail Inmates at Midyear report, 2004. This is not counting those under bail, probation, parole, or hiding from the Justice system etc. In contrast, 1 in 28 Hispanic males and 1 in 59 White males were incarcerated in the same age group.

${ }^{2}$ See for example the vivid excerpts from Black female interviewees in Lane et al. (2004).

${ }^{3}$ This imbalance is made even worse by the greater tendency of Black males to marry non Black females than the reverse, the greater enlistment in the military, the higher mortality rate among adult Black males, the higher rate of mental institutionalization, etc. (Tucker and Mitchel-Kernan, 1995).
} 
It is conceivable that a growing fraction of young Black women would decide to forego early motherhood, continue their studies or become financially independent through employment because of the mass confinement, hence shortage, of Black men. Indeed, the Black non-marital teen pregnancy rate, although higher in absolute terms, has decreased faster than its White counterpart in the last fifteen years (National Center for Health Statistics [NCHS], 2005). Further, Black women catch up in education (Allen et al., 2005) and in the labor market (Offner and Holzer, 2002; Western and Pettit, 2005) better than Black men relative to Whites.

To examine how the rising levels of incarceration of Black men lead young Black women to change important lifetime decisions I compiled data on the number of male prisoners by race, gender, state and year from the Bureau of Justice Statistics (BJS). From there, I constructed male prison rates per adult male population using the U.S. Census. I tapped into a rich set of individual-level information on fertility, schooling, marriage and employment from the June and March supplements of the Current Population Survey (CPS). I then merged (Census adjusted) BJS prison statistics with CPS data so that they match on a race, year and state basis. The benchmark Ordinary Least Squares (OLS) model allows for disentangling incarceration paths from state effects, year effects and secular trends in socio-economic changes within states. I then use weights, a Black/White comparison and Instrumental Variables (IV) to test the robustness of the OLS results.

To summarize, I find that higher rates of Black-male incarceration have lowered the odds of non-marital teenage fertility among young Black females. I also find a sizable, significant and positive effect of Black-male incarceration on single Black women's school attainment and employment in their early twenties. This may explain the negative impact of Black-male 
incarceration on young White female employment. Finally, I cannot rule out a zero effect of Black-male incarceration on the probability of marriage for young Black women.

This work relates to several branches of a literature spanning different disciplines. Social scientists have long been intrigued by the consequences of sex ratio imbalances. In an influential book, Wilson (1987) expressed concern over the decline in acceptable marriage partners, or "quality men” in the Black community, usually defined as men with a stable job. Wilson’s ideas sparked a body of research on the impact of “quality men's” scarcity (Horton and Burgess, 1992; Lichter et al., 1992; Kiecolt and Fossett, 1997; Neal, 2004). However, male (un)availability originates from multiple factors that were often left aggregated. Each of those factors, in turn, may have a different effect that needs to be separately estimated.

As economic conditions improved in the 1990s, incarceration pursued an exponential trajectory. ${ }^{4}$ Legal scholars, psychologists and sociologists devoted more attention to the consequences massive incarceration may have on inner cities communities (Vera Institute of Justice, 1996; Lynch and Sabol, 2003a and 2003b). Still, according to Hagan and Dinovitzer (1999), little work has been done on the effects of imprisonment on family structure. ${ }^{5}$

Looking into the contribution of economics to crime and policy issues, most of the work has focused on the criminals themselves, whether on the determinants of criminal activity, the deterrence effectiveness of various policies, or the labor market consequences of incarceration

${ }^{4}+360 \%$ in prisoners per inhabitant alone between 1978 and 2004 - see Mincy, (2006).

${ }^{5}$ Some research has investigated the impact of incarceration within the inmates' families (Western and McLanahan, 2000; Thomas, 2006; Oliver et al., 2006), yet not on single women who are among the secondary victims of massscale male incarceration (Garland, 2001; Mauer and Chesney-Lind, 2002; Meares, 2004). 
after release from prison. The role of aggregate male incarceration on single women's fertility, human capital accumulation and employment decisions has been neglected.

The present study is closest to that of Charles and Luoh (2006) which estimates the impact of male incarceration on selected female outcomes. Charles and Luoh (2006) observe that women overwhelmingly marry slightly older men from the same race and state. Since the U.S. decennial Census tells us who is institutionalized, which is approximately the same as incarcerated, they use the last four waves of that data set to match outcomes of women of different age groups, race, and state to the corresponding incarceration rates among slightly older men. Charles and Luoh (2006) find that rising levels of male incarceration have lowered the likelihood that women marry and have caused a shift in the gains from marriage away from women. In response to these changes, they also find that women have increased their schooling and labor supply.

This study differs from Charles and Luoh (2006) on several counts, mainly: (1) while the BJS does not break prisoner data by age for each state, gender, race and year, the advantage is that I dispose of more waves, therefore I can better pinpoint which period is driving the results; (2) I use male incarceration rates preceding the outcomes under investigation ${ }^{6}$; (3) I use individual, not aggregated data; (4) I apply an alternative set of IVs to validate the robustness of the results; (5) as a matter of exposition, I differentiate my results by racial groups - focusing on Black women - as opposed to leaving them averaged, which reveals additional insights.

The conclusions of the present paper complement but also contrast with those of Charles and Luoh (2006) concerning the outcomes we both analyze. I find that the effect of male incarceration on female education is positive, but in a consistently significant way only within the Black sample. Further, I find that in response to Black-male incarceration, the increase in

\footnotetext{
${ }^{6}$ More generally, I am not constrained to use those rates concomitant to the observations.
} 
Black women employment actually exceeds the decrease in White women employment. Finally, my conclusion on the effect of male incarceration on marriage is less assertive.

\section{Methods and Estimation Strategies}

Let us consider a model estimating the impact of male incarceration on any single female outcome: Outcome $=\alpha+\beta$ Incarceration $+\sum_{j} \lambda_{j}$ Characteristics $_{j}+\varepsilon$.

The main difficulty in assessing this relationship lies in the assignment of incarceration rates to individual observations. At the aggregate level, large male-incarceration rates should have some impact over a female individual's lifetime, yet which ones to choose? Certainly, a matching based on race and state is intuitive. ${ }^{7}$ But at what age are these rates most relevant? Also, should the researcher take a (weighted) average local male-incarceration rate over a certain number of years before the time when the individual is observed? The absence of definite, undisputable answers to such modeling questions must have played a role in the relative absence of quantitative studies on this issue.

This is why the present work focuses on unmarried women in their late teens and early twenties. First, this narrow age range corresponds to a particularly critical point in a woman's life-cycle; that is, when she is at risk of not completing high school, of becoming a single teenage mother and not joining the labor market. Second, if local incarceration plays a role in

${ }^{7}$ The fraction of Black women marrying non-Black men has been less than $5 \%$ on average in the last thirty years (U.S. Decennial Census 1980, 1990 and 2000) - see also Brien (1997). Similarly, the percentage of marriages where the bride and the groom are residents of different states is negligible. 
such decisions, it is likely that the most influential incarceration rate is that which immediately precedes those decisions. At the very least in this way one conservatively limits the chances of mismatch between relevant incarceration rates and outcomes of interest. I thus chose a one-year lag between incarceration rates and observed outcomes to capture the response of women to the latest incarceration rate they have experienced. In other words, for all the estimations, the male incarceration rate at the end of year $\mathrm{t}-1$ is matched with observations in year $\mathrm{t}$ :

$$
\text { Outcome }_{i s t}=\alpha+\beta \text { Incarceration }_{\text {st }-1}+\sum_{j} \lambda_{j} \text { Characteristics }_{i s t j}+\varepsilon_{i s t}
$$

where i, s, t index the individual, state and year respectively.

I assume throughout that decisions made by young women do not cause the behaviors that result in men being incarcerated, such as drug possession or violent crimes, nor that they cause the policies that influence incarceration, such as sentencing changes, changes in law enforcement personnel per capita or prison constructions. A related concern is that women's decisions are driven by males' conduct. In that case, young women would change their behavior over time because men are becoming worse bets as husbands, not because they are locked up. However, there is evidence that changes in male-incarceration rates over time are not caused by changes in male behavior but rather by changes in policy. ${ }^{8}$

BJS statistics show that violent crime exhibited no clear direction from the early 1970s up to the early 1990s and has been rapidly going down since. For drug charges, according to the U.S. National Household Survey on Drug Abuse, an estimated 14.8 million Americans, about 6.7\% of the household population age 12 and older, used illegal drugs on a current basis in 1999. Note

\footnotetext{
${ }^{8}$ This argument enables us to counter the hypothesis that Black-male incarceration is partly a consequence of Black female empowerment (precisely, through increased schooling, employment etc.). The possibility of reverse causality would have made the problem infinitely more complex to analyze.
} 
that the proportion of Blacks is close to that of Whites (7.7\% vs. 6.6\%) even though Blacks are arrested on drug charges at several times the rate of Whites (the racial disparity in arrests on drug charges increases significantly over the period). This number of past-month drug users declined by more than $50 \%$ from the 1979 high of 25 million (14.1\% of the population). This is precisely the beginning of the period covered here. ${ }^{9}$ The discrepancy between increase in incarceration and decline in criminal behavior is mainly the result of the so-called War on Drugs. Similar drug offenses, notably possession - for which, again, prevalence does not increase - are prosecuted more aggressively, resulting in a higher likelihood of being brought to courts. ${ }^{10}$ Accordingly, states are simply putting more drug users in prison than before, and more precisely minor drug users whose actions would not directly affect women’s key lifetime decisions.

This being said, the interpretation of male incarceration effects on women is in principle twofold: the removal of some men from the population (direct effect) and the tougher approach to crime inducing better behavior among those who are not arrested (indirect effect). Given that incarceration increases by many times more than the decrease in criminal behavior during the period, it is legitimate to consider that the direct effect dominates the indirect effect. In the following discussion, I therefore interpret the effect of incarceration as mostly the direct effect.

Still, the identification of the causal impact of incarceration is not straightforward because of the numerous potential confounding factors associated with incarceration. It is well known that

\footnotetext{
${ }^{9}$ Charles and Luoh (2006) concur based on juvenile statistics (a good predictor of future adult behavior).

${ }^{10}$ According to Charles and Luoh (2006), the fraction of drug offenders increases because a higher fraction of cases brought to state courts are drug related. In contrast, for all drug charges, they do not detect a change in the probability of conviction, or a change in the probability of imprisonment conditional on conviction, or a change in the average sentence conditional on imprisonment.
} 
using a single cross section to tackle such a problem is inadequate. When pooling cross sections, year effects control for the evolving unobserved national attributes that affect the different outcomes of interest. Similarly, state fixed effects control for time invariant unobserved influences that vary across states. Yet, the factors that affect incarceration may also vary within a state over time: simply controlling for year and state effects could still bias the estimation of the incarceration coefficients. ${ }^{11}$ To cope with this problem, the specifications can be made more flexible by adding interaction terms between state effects and a time trend and between state effects and the square of a time trend (Friedberg, 1998). These terms, therefore, capture all drifts in state-level characteristics that influence the outcomes of interest with the slopes of those trends allowed to vary smoothly within states. Such local changes can be of political, socioeconomic or demographic nature. The benchmark model can be rewritten, with standard notations:

$$
\begin{aligned}
\text { Outcome }_{\text {ist }}= & \alpha+\beta \text { Incarceration }_{\text {st }-1}+\gamma 1_{t}+\delta 1_{s}+\mu\left(\text { Trend }_{t} \times 1_{s}\right)+v\left(\text { Trend }_{t}^{2} \times 1_{s}\right) \\
& +\sum_{j} \lambda_{j} \text { Characteristics }_{\text {ist }}+\varepsilon_{\text {ist }}
\end{aligned}
$$

In theory, variations across time and within states translating into discrete jumps in incarceration rates would provide an excellent source of identification that enables disentangling incarceration paths from state effects, year effects and secular trends in socio-economic changes within states. In practice, however, it can be observed that in almost every state, incarceration increases every year over the period, although not always at the same rate, which is of course crucial. In other words, the causal effects of incarceration need to be identified against the

\footnotetext{
${ }^{11}$ This would happen if those changing factors within states are correlated with variations in incarceration and if such factors do not change at a national level uniformly and do not get picked up by the year effects.
} 
distinct trends that characterize incarceration paths. At the state level, there is just enough variability around a linear-quadratic trend for adequate identification. ${ }^{12}$

Notwithstanding the difficulty, I use linear probability models which, in the most informative specifications, control for year effects, state effects and state linear and quadratic time trends. Because of the "black box" nature of this approach, I further try to characterize which are the main variables potentially correlated with incarceration that those state-level trends absorb. I also add some specific variables that change within state over time in some robustness checks. I include the respondent's age in all the estimations. Robust standard errors account for the heteroskedasticity of the error terms, and various specification checks use different clustering approaches to allow for the possibility that outcomes be correlated within certain groups.

To provide additional robustness to the results, I use three different strategies. First, the effects should be better captured in the more heavily populated states if criminal activity (hence arrests) exhibits increasing returns with respect to population density, which is correlated with population size. Alternatively, in some states, the sheer small number of Black male prisoners in some years fewer than ten (in five states) - makes any inference problematic. Therefore, by weighting the regressions using number of adult Black males in each state/year, the coefficients, although carrying a slightly different interpretation, should be more precisely estimated.

Second, I expect a stronger impact of incarceration for Blacks than for Whites. This is because the Black teenage fertility rate is higher, while the female educational achievement and labor-force participation are lower than those of Whites. Alternatively, even if there is no racial difference but the effect of male incarceration on females is nonlinear, given that Blacks are on

\footnotetext{
${ }^{12}$ I am thus "pushing the limits” of the identification strategy. To give an idea, an OLS estimation of adult Blackmale incarceration rates on a linear and a quadratic trend alone would yield an adjusted $\mathrm{R}^{2}$ over 0.9 in most states.
} 
average eight to nine times more likely to be incarcerated than Whites, an interaction term Black $\times$ Incarceration will specifically reflect this nonlinear impact. To that effect I assign the White-male incarceration rate to White females and the Black-male incarceration rate to Black females and run regressions over both groups. However, Whites are not a perfect control group for Blacks; rather I am evaluating treatment intensities in two groups that otherwise differ systematically. To control for such differences, I control for the race-specific incarceration rate and add all the other controls (year effects, state effects, etc.) interacted with the White/Black dummy. The interpretation of the interaction term coefficient is then the pure differential effect of incarceration between Blacks and Whites, and the race-specific coefficient becomes mechanically the incarceration coefficient for the White group only. With standard notations:

$$
\begin{aligned}
\text { Outcome }_{\text {irst }} & =\alpha+\beta \text { Incarceration }_{r s t-1}+\phi\left(\left(1-1_{r}\right) \times \text { Incarceration }_{r s t-1}\right) \\
& +\gamma 1_{t}+\delta 1_{s}+\mu\left(\text { Trend }_{t} \times 1_{s}\right)+v\left(\text { Trend }_{t}^{2} \times 1_{s}\right) \\
& +\sum_{j} \lambda_{j} \text { Characteristics }_{\text {irstj }} \\
& +1_{r} \times\left\{\gamma 1_{t}+\delta 1_{s}+\mu\left(\text { Trend }_{t} \times 1_{s}\right)+v\left(\text { Trend }_{t}^{2} \times 1_{s}\right)\right. \\
& \left.+\sum_{j} \lambda_{j} \text { Characteristics }_{\text {irstj }}\right\}+\varepsilon_{\text {rist }}
\end{aligned}
$$

Third, because incarceration rates might still pick-up effects not captured by the controls and that would simultaneously determine female outcomes, I instrument incarceration. Sentencing change are natural IV candidates: changes in sentencing policies occurred at the state level throughout the 1970s, 1980s and 1990s in most states. Given the political nature of the determinants of these laws (Dharmapala et al., 2006) it is unlikely that they are related to young women's decisions regarding fertility, education, marriage or employment. Note that changes in state criminal codes do not occur in response to an increase in crime either. 
I considered all possible combinations of: (1) determinate sentencing (i.e., the abolition of discretionary parole release), (2) alternative indicators of parole restriction ${ }^{13}$, (3) structured sentencing (recommended prison terms for offenses), either with presumptive sentencing (systems of single recommended sentences for each offense or offense class), or with presumptive or voluntary guidelines (systems of multiple sentence recommendations for each offense or offense class), (4) provisions enhancing sentences for second- and third- time offenders, violent offenders or drug offenders, (5) enactment by the states of the Federal Truth in Sentencing (TIS) program ${ }^{14}$ and (6) "three-strikes" laws. While the effects of those policies may at times appear to differ from their stated objectives, what matters for our purposes is (their plausible exogeneity and) the magnitude of their impact. ${ }^{15}$

Another determinant of incarceration is prison capacity. Capacity is appealing as an instrument because decisions to build may take more than a decade before translating into operational facilities. Levitt (1996) documents the lengthy course of prison overcrowding

${ }^{13}$ Determinate sentencing as reported by the states themselves, as opposed to the previous, more academic classification, as well as a synthetic indicator combining the above.

${ }^{14}$ Many states have sought greater determinacy through the adoption of federally-funded TIS laws. In 1994, the federal government enacted legislation creating TIS grants for states. Under the program, states requiring violent offenders to served $85 \%$ of the sentence imposed by the court could receive funding from the federal government to expand jail and prison capacity and to ensure that prison space was reserved for violent offenders.

${ }^{15}$ See Stemen et al. (2005) for the reasons why determinate sentencing may in fact be expected to reduce prison population. This is consistent with Myers’ claim: “ironically sex-ratios in recent years are slightly higher for Blacks in sentencing guidelines states than there are in non-sentencing guideline states.” (Myers, 2000) 
litigation. In particular, he shows that states where overcrowding lawsuits are filed have higher than average incarceration growth rates before the filing and shorter ones afterwards. A common outcome for a state that has been sanctioned by courts for its prison overcrowding practice is to build new facilities. Even though overcrowding litigation is not the only reason for the building of new prisons, the consequence of capacity expansion for incarceration is important: as long as prison overcrowding prevails, judges who are aware of the situation may be reluctant to send minor criminals to prison and may prefer to sentence them to probation. Similarly, at the margin, parole boards should be more generous in granting release and probation officers more hesitant to revoke paroles. Once new facilities are built, the capacity constraint is not binding any more. Empirically, this conjecture is validated for parole more than for probation. I find that in many states, following an increase in prison capacity, the growth of parolees slows down or their number may even drop. Most importantly for our purpose, the proportion of offenders sent behind bars increases accordingly.

Although I could not find a systematic study on this phenomenon, ${ }^{16}$ there is evidence in the data to support this causation mechanism, and it appears to be part of the culture of the numerous state department of corrections officials I talked to. ${ }^{17}$ The opening of new facilities and the change in incarceration they induce should be, from the perspective of the young women I observe, largely exogenous.

${ }^{16}$ This is reminiscent of the popular movie line "If you build it, they will come” (Field of Dreams).

17 To give but one recent example, a new prison was opened in Maine in early 2002, and the state prison population suddenly spiked by more than $11.5 \%$ - by far the highest growth rate in the U.S. that year (average: $2.6 \%$ ). Previously the annual growth rate in Maine had been running below $2 \%$.

See http://www.maine.gov/corrections/Facilities/msp.htm. 
When choosing those variables that will eventually be used in the Two-Stage Least Squares (2SLS) estimation, I use a conservative procedure. I run first-stage regressions on the source file (adult Black-male incarceration rate for the 50 states + D.C. and 22 years - one observation per state/year) and select those variables, from the list of sentencing policy and capacity expansion changes, which are significant. I then perform similar first-stage regressions using observations from the different CPS samples. To err on the safe side, I only select a variable to be a suitable candidate if it is significant in all estimations. Since I have two different sets of potential IV, I test the soundness of each instrument by running tests of overidentifying restrictions (see Wooldridge, 2000). The variables that pass all those filters are then considered valid IV. Table 3 shows the first stage for the different samples used. ${ }^{18}$

\section{Data}

This work uniquely combines different data sets to assess the impact of Black-male incarceration rates on Black female outcomes. My statistics for incarceration come from the “Correctional Population in the United States” series (1985-2003) and "Prisoners in State and Federal Institutions on December $31^{\text {st”, }}$ series (1978-1984), both from the BJS. Prison statistics by race were first released in 1978. Coincidentally 1978 roughly corresponds to the beginning of the giant wave of incarcerations that has been sweeping the United States since.

\footnotetext{
${ }^{18}$ Because the parole restriction indicator and TIS are highly correlated (see Dharmapala et al., 2006 and Table 2), the individual coefficients may not always be significant in the first stage, but they are significant when one variable is included exclusive of the other, and they are also jointly significant.
} 
With a few exceptions, these data give the numbers of prisoners by race for every year in every state. $^{19}$ I focus on prison statistics because of the misleading and inconsistent nature of jail statistics. $^{20}$ I cannot subtract the number of federal prisoners from total prisoners in each state and year, so the numbers collected represent both types; however, the overwhelming majority of prisoners are state prisoners $\left(89 \%\right.$ in 2000). ${ }^{21}$ Note that the proportion of state prisoners incarcerated in a state different from the one they lived in at the time of committing their offense is negligible and does not affect the assignment of prisoners by state. ${ }^{22}$ This is of great importance because it gives us confidence that the evolution of male incarceration in one particular state would directly affect females in that state. ${ }^{23}$

\footnotetext{
${ }^{19}$ A difficulty when assembling a time series for White prisoners at the state level is that there was no specific category for Hispanic prisoners before 2000. States were free to include Hispanics under Whites or categorize them as Unknown Race. To make matters worse, some states changed their labeling over time, making comparisons across years difficult. With great caution, I retained as much information I could while taking as few and as sure guesses as possible, so that within each state, the White male prisoners' series displays consistency. These considerations only play a role for the estimations requiring data on the number of White male prisoners as well.
}

${ }^{20}$ It is difficult to separate jail and prison populations and to prevent double counting as more jails began to hold state and federal prisoners through the years. In a few small states, the prison figures used include both jail and prison inmates because jails and prisons are combined into one system in those jurisdictions.

${ }^{21}$ Federal prisoners may be held in another state because of the relatively small number of federal prisons.

${ }^{22}$ Some states use other states' facilities to hold some of their populations. Yet, even if state prisoners are held outside a state prison, they are in their jurisdiction counts, even if another State has actual custody.

${ }^{23}$ It is of course possible that a criminal committed an offense in a state in which he does not live. Charles and Luoh (2006) present evidence that this is negligible. 
To transform the raw figures of inmates into percentages of the adult population in each year and state, I use the U.S. Census Estimates 1970-2000 provided by the Center for Disease Control (CDC) Wonder website which gives in each state and year the number of inhabitants by gender, race and 5-year age group. Since roughly $95 \%$ of prisoners are between the age of 20 and $54^{24}$ for each race, I use the number of males age 20-54 as the deflator. This adjustment seems more accurate than taking the total number of males in a state because of the changing demographics over the period such as increase in longevity or decline in infant mortality. At the state and race level, the evolution of male incarceration rates per 20-54 male population proxies reasonably well for the evolution of incarceration rates most significant to young women e.g., that of males slightly older than them. In any case, as incarceration is rising over time and feeds mainly from men in their 20s and 30s, the incarceration rate of men age 20-54 systematically underestimates the most relevant incarceration rates. Thus, the effects found in this study may be viewed as a lower bound of the true effects I try to measure.

The main independent variable of interest is the incarceration rate of Black males per 20-54 Black male population. Table 1a presents descriptive statistics for all fifty states: note that min. and max. values correspond in all but a few cases to the two end points of the period, 1978 and 1999. Table 1b presents those same statistics with states grouped in regions by Circuit Court. Apart from Circuit Court 1, average incarceration is fairly uniform over the country, although a

\footnotetext{
${ }^{24}$ Nothing can be done to encompass those offenders age 18-19 since the CDC Wonder site does not break population by individual age, only age brackets. However, to give an idea, less than $3 \%$ of all Black male prisoners were age 18-19 in 2000 - as opposed to less than 2\% for those age 55 and above (BJS Prisoners in 2000, Table 14), which is an upper bound for the entire period.
} 
few states play a disproportionate role in the empirical estimations. Graph 1 shows the average incarceration rate of Black and White males per 20-54 male population over time in the U.S.

I use CPS data for the dependent variables and covariates. For the estimation of teenage fertility, the information comes from the June CPS. I use the variable "number of babies" to construct an indicator for whether a woman has had a child. ${ }^{25}$

In Graph 2 I plot the total teenage pregnancy rate by race for women age 18-19 from 1964 to 2001 from the NCHS. Graph 2 shows a relative stability among White females over the entire period: more precisely, an increase in the late 1980s to early 1990s, followed by a decrease later on. For Black females, the same movement occurs in the late 1980s and early 1990s but the decline is more pronounced. The general decline over the 1990s led a columnist to write:

In the past decade, possibly no social program has been as dramatically effective as the effort to reduce teen pregnancy, and no results so uniformly celebrated. Between 1990 and 2000 the U.S. teen pregnancy rate plummeted by 28 percent (...) Births to teenagers are also down, as are teen abortion rates. It's an achievement so profound and so heartening that left and right are eager to take credit for it, and both can probably do so. (Mundy, 2006)

\footnotetext{
${ }^{25}$ Prior to 1990 , fertility questions were only asked to married women only or women 18 and above. Years 1986 1988 are excluded because the question on fertility was asked to married women only. Also, fertility was not part of the questionnaire in 1991, which leaves us with 1979-85, 1990, 1992, 1994-1995, 1998, and 2000.
} 
Many hypotheses can be advanced to account for this phenomenon: liberal sex education, abstinence initiatives, welfare reforms, etc. Be that as it may, it is unclear from a graphical observation alone whether male incarceration rates contributed to the decline in teenage motherhood.

I am also looking at education, labor-force participation and marriage. For those variables, I use the March CPS data since the collection does not contain gaps. For education, I focus on the highest grade attended at age $20{ }^{26}$ A methodological challenge arises: it is well known among CPS users who have studied education over time that the coding of education changes between the pre-1992 and post-1991 periods. Unfortunately, there is no satisfactory recode that would make the series perfectly consistent over the two periods. The recode proposed by Jaeger (1997) is the most intuitive and I therefore adopt it. Finally, I investigate attachment to the labor force using different measures: full-time employment, labor force participation, and hours worked per week for several age groups between 18 and 25.

In Graphs 3 and 4, I use the Statistical Abstract of the U.S. and the Census School Enrolment Tables to plot educational attainment of women for age 25-29 and age 18-24, by race. We observe a convergence in attainment between Black and White females regarding high school completion, but the convergence trend started well before the mass incarceration movement. The gap for college enrollment and completion slightly widened because the proportion of White females who go to college increases faster than its counterpart among Blacks. In particular, the proportion of White female college graduates increased throughout the period. In contrast, the

\footnotetext{
${ }^{26}$ Note that it would be hazardous with non-longitudinal data to recover education at age 20 of individuals older than 20, and subsequently match them with incarceration rates at age 19, assuming those people did not move across states in the meantime.
} 
1980s are a lost decade for Black women regarding education. Yet, after the slight decline of the 1980s, the proportion of Black women with a four-year degree or enrolled in college picks up again in the early 1990s, not long after an increase in the growth rate of male incarceration in the late 1980s. However, the evidence of a link between the two patterns is unclear.

In Graph 5 I describe the evolution of full time employment for young women by race and different age brackets (the variable "work status” is missing in 1994 and 1995, hence the gap). ${ }^{27}$ The most striking feature of Graph 5 is the catch-up between Black and White women over the period. We note a general decrease for Whites as well as a slight increase for Blacks, especially in the 1990s. While it is not apparent that incarceration rates can explain the convergence, the absence of decline in young Black-women employment rates warrants an explanation.

In Graph 6 I look at the proportion of women never married by race and age brackets. The essential feature is a continuous evolution capturing the decline in the institution of marriage, for both Blacks and Whites, for all ages. Although the slopes are similar, the levels between Black and White marriage rates are different. White women are still more likely to be married than Black women. The graph does not support the hypothesis that marriage and male incarceration are causally related since the growth in male incarceration is much faster than the growth in the proportion of never-married women (especially for Blacks).

To construct the sentencing changes-based IV I used the compilation prepared by the Vera Institute of Legal Research (Stemen et al., 2005), the report on the influence of TIS reforms

\footnotetext{
${ }^{27}$ Female employment increased at a declining rate from the late 1970s to the early 1990, after which it leveled off before picking up again in the mid 1990s. In recent years, much of the increase in women's labor force participation can be attributed to the rising participation rates of women with young children. I emphasize that the participation rate for women 16-24 years old has been a major source in the deceleration of female employment in general.
} 
prepared by the Urban Institute (Sabol et al., 2002), and the BJS report on TIS in State Prisons (Ditton and Wilson, 1999). For measures of prison capacity in each state and year, I use the yearly publication "Prisoners in Year X" published by the BJS at the state level only since 1983. However, the collection of this statistic is imperfect: it is available for only half of the ((50 states + D.C. $) \times(1999-1982)=867)$ possible observations. Therefore, I use dummy variables to capture the most dramatic increases in prison capacity that occurred in those states where such a pattern can be found. ${ }^{28}$ Still, this method has the advantage that it does not drop any observation. I provide the illustrative example of Texas in Graph 7. It shows the concomitant dramatic increase in prison capacity and Black-male incarceration starting in the mid-1990s, as well as the decrease in the number of adult offenders on parole during that same period.

To summarize, the sentencing changes that significantly influence Black incarceration (i.e., the first stage) in all models are a synthetic indicator of parole restriction, ${ }^{29}$ TIS and presumptive sentencing (the much publicized "three-strike laws" do not have a significant impact on incarceration). Table 2 provides dates following the year of enactment for each state. ${ }^{30}$ The prison capacity change dummies that pass all the filters originate from California, Texas,

\footnotetext{
${ }^{28}$ Put differently, this translates into not creating dummies in those states where capacity increases with time without significant jumps or where there are too many missing observations.

${ }^{29}$ This is consistent with Greenberg and West (2001) and Jacobs and Carmichael (2001).

${ }^{30}$ Note that, for example, parole restrictions occur in 16 states, as different in social climate as Kansas and Oregon, and throughout the period considered here so that the identification does not originate from a limited area or period.
} 
Wisconsin, Massachusetts, and West Virginia (dates given in Table 3). ${ }^{31}$ Some variables pass some but not all of the filters and I use those for additional robustness checks. Fortunately, none of the instruments are rejected according to the Sargan tests. For both the June and March CPS samples, the resulting F-test from the first stage, i.e., testing that all eight instrument coefficients are jointly equal to zero, is high (between 37 and 121): it strongly rejects the hypothesis that the instruments have no effect on incarceration.

\section{Results}

\section{1. Fertility}

The results in Table 5 support the hypothesis that Black-teenage fertility declined as a consequence of increased Black-male incarceration. I present different estimations of the model that provide insight into the identification of the parameter of interest. Recall that the incarceration movement is in almost every state increasing with time monotonically. Without any control, the first estimate in column (1) is positive and insignificant in the same way a simple time trend happens to be positive and insignificant. The explanatory power of the model, captured by the adjusted $\mathrm{R}^{2}$, is very small. This is driven by the increase in teenage fertility that characterized the mid-1980s to early 1990s and hides the more general pattern of secular decline over the second part of the 20th century.

\footnotetext{
${ }^{31}$ Some states yield good first stage results in the source file but there are no observations from those states in our main CPS samples. Since they also perform well in the first stage in some robustness checks when enlarging the samples, I also mention them here. These states are: North Dakota, South Dakota, New Hampshire, and Maine.
} 
The results presented in column (2) take time effects into account: Black-male incarceration is still positive and insignificant. The incarceration coefficient is still uninformative, picking state fixed and dynamic effects. The adjusted $\mathrm{R}^{2}$ rises marginally (+10\%). Regression (3) adds state fixed effects. The increase in adjusted $\mathrm{R}^{2}(+67 \%)$ indirectly confirms the contamination of the incarceration coefficient in equation (2). The coefficient is now negative, but still insignificant. Incarceration may be here confounded with patterns that shift at the state level: as argued earlier, assuming these patterns are constant within a state or changing over time but uniformly across the nation is overly restrictive.

When adding state-level linear and linear-quadratic time trends, in columns (4) and (5), the coefficient on incarceration remains negative but now becomes more precisely estimated and significant. An F-test on all state linear trends rejects the null hypothesis in model (4), and so does an F-test on all state linear and quadratic trends in model (5). The interpretation of the coefficient is now easier since incarceration is purged of the local effects previously picked up which, to the extent that they change slowly over time, are now well captured by the trend terms. The increase in adjusted $\mathrm{R}^{2}$, although small $(+13 \%)$, is noticeable given the large number of variables added. Yet, in model (5), the quasi stability in adjusted $\mathrm{R}^{2}$ compared to model (4) tells us that there is nothing to be gained by adding even higher-order terms. Clustering standard errors by state or by state and year would produce similar significant results.

A comprehensive sensitivity analysis yields the following results. When dropping one Circuit Court at a time from model (5), all results hold except when removing Circuit Court 5. Digging further, the $5 \%$ significance level breaks down if Texas alone ( $5 \%$ of the sample) is removed - although removing Texas during the 1980s only would leave the results unaffected. This indirectly confirms the role of the dramatic and much publicized increase of incarceration in 
Texas: it suggests a steep marginal effect of incarceration beyond a certain threshold. ${ }^{32}$ To confirm this intuition, I partitioned the sample to single out those states which, at the end of the 1990s, reached Texas-like rates of adult Black male incarceration (in particular, Connecticut, Delaware, Iowa, Oklahoma, Rhode Island, Wisconsin): keeping those states only, plus Texas and Washington D.C., yields a 1\% level coefficient with only 783 observations, that is, $15 \%$ of the sample. Conversely, running model (5) on all other states yields an insignificant point estimate. Moving to checking the sensitivity of the results to the period considered, eliminating the 1980s leaves the main result significant at the $5 \%$ level (with only $39 \%$ of the sample left); actually keeping only $1992-2000$ is enough to retain a $10 \%$ level (31\% of the sample left). On the other hand, eliminating the 1990s leaves the result insignificant. Indeed, the $5 \%$ significance level breaks even if one only removes 1998-2000 (with 89\% of the sample left).

Adding a dummy variable coding for governor's party or a variable for state-level Black male unemployment does not change the results. The results were also unchanged when adding variables corresponding to different ratings of state generosity under the Temporary Assistance for Needy Families (TANF) program (see Waldfogel, 2004). ${ }^{33}$ These variables, however, are

\footnotetext{
${ }^{32}$ I also tested the hypothesis that the changes driven by the inclusion of state trends reflect the rapid increase in Hispanic population in some states. However, when removing states other than Texas with a large Hispanic population (California, New York, Florida, Illinois, Arizona and New Jersey), the results are virtually unchanged.

${ }^{33}$ The stated purposes of TANF are to: (a) Provide assistance to needy families so children may be cared for (b) End the dependence of needy parents on government benefits by promoting job preparation, work, and marriage (c) Prevent and reduce the incidence of out-of-wedlock pregnancies and (d) Encourage the formation and maintenance of two-parent families.
} 
jointly significant. ${ }^{34}$ The role of welfare reforms in the second half of the 1990s makes it clearer why including time varying effects within states is so crucial hence the abrupt change in the coefficient and significance from model (3) to models (4) and (5): large funding differences between the states in the TANF block grant contribute to disadvantage many states. Moreover, states have broad discretion in their use of TANF funds. ${ }^{35}$ At the same time, it is plausible $a$ priori that drastic changes in state-level welfare generosity, while not necessarily causal in nature, would be correlated with state-level incarceration policy, both of which being bent by the same "tougher" ideology towards social issues and by an evolution of local norms regarding tolerance and work ethics. Finally, when regressing Black fertility on both Black and White male incarceration, only the Black incarceration rate is significant.

Looking at the preferred estimation (model 5), the magnitude of the effect is sizable: at the means of the data, a $1 \%$ increase in the adult Black-male incarceration rate (per adult Black-male population 20-54 y/o) decreases the probability of having a child by 0.04 . Recall that the

\footnotetext{
${ }^{34}$ This result accords with the findings of Offner (2003) and Kaestner, Korenman, and O'Neill (2003). Given the importance of the sub-period 1996-2000 it is possible to check whether the effects of TANF amplify the impact of incarceration: looking at different interaction terms between incarceration and state-level TANF ratings, only one is significant at the $5 \%$ level.

${ }^{35}$ States differ in the limit on receipt of cash assistance, in the maximum amount of earnings that a family can have and still be eligible for cash assistance, in the option to rescind eligibility rules that penalize marriage, in sanctioning policies for failure to comply with work-related requirements, in the allocation of diversion payments, in spending on abused and neglected children, in foster home licensing standards and procedures, in providing health insurance coverage beyond the federally mandated minimums, in policies that allow families to receive a lump-sum payment rather than formally enroll in the cash assistance program, etc.
} 
average proportion of mothers in this sample is about 30\%. Given an average adult Black-male incarceration rate of close to $4 \%$ this corresponds to an elasticity of -0.53 .

The presentation of this result becomes perhaps more compelling if we compare the effect of incarceration with that of age: in absolute terms, the decline in teenage fertility associated with a $1 \%$ increase in adult Black male incarceration rate is equivalent to the expected average increase in teenage fertility associated with seven extra months of age at age $19 .^{36}$ I suspect that the effect would be even greater if I could more specifically capture the incarceration rate of younger adults.

Given the drop in uncontrolled average non-marital teen pregnancy among Blacks over the whole period, and since White non-marital teen fertility is approximately stable at the same time, it is useful to compare the effect of incarceration with the efficiency of more direct and targeted policy measures which take credit for the success in reducing teen births in the U.S. For example, most TANF variables coefficients are statistically significant and two to four times larger than the incarceration coefficient (in order of increasing magnitude: sanctions, earnings disregards, time limits and benefit generosity).

I apply different methods to affirm the robustness of these results, all of which make use of the controls included in model (5). First, I use weights corresponding to the adult Black male population 20-54 in each state and year. Model (6) yields a slightly higher point estimate and, as expected, an improved statistical precision.

Looking into the Black/White comparison, the interaction coefficient Black $\times$ incarceration rate in model (7) shows that in response to male incarceration in their group, Black females

\footnotetext{
${ }^{36}$ The effects are also strong and significant when considering the total number of births ( $8 \%$ of the sample has more than one child) instead of the dichotomous variable "motherhood".
} 
reduce their fertility relative to White females. Conversely, in the White population in the same age range, the effect measured here by the racial-specific incarceration coefficient, is actually positive, yet insignificant. $^{37}$

Finally, I run a 2SLS estimation using carefully selected sentencing changes and prison capacity changes as instruments. When using the full set of instruments, the benchmark IV results confirm the previous analysis and the coefficient is significant at the $5 \%$ level. Although the point estimate is higher, I cannot reject the hypothesis that the IV coefficient is equal to the OLS coefficient. Additionally, the average incarceration rate is more than $13 \%$ higher in the states that contribute to the identification than in the others. This could explain the discrepancy in point estimates. When I relax some of the filters on the validity of the instruments, such as requiring them to work for the CPS sample but not necessarily in the source file, the precision is improved.

Overall, the results on fertility converge to the conclusion that the sheer magnitude of adult Black-male incarceration is enough to significantly reduce Black teenagers’ non-marital fertility. This conclusion goes against the qualitative argument that the smaller number of men leads to more bargaining power on the male side and in turn, more extra marital relations and pregnancies (Courtwright, 1996). Quantitatively, my results run opposite to those of South and Lloyd (1992) who found that in 1980, male scarcity broadly defined had no significant effect on the nonmarital fertility rate for any age range among Blacks. ${ }^{38}$

\footnotetext{
${ }^{37}$ I could not find plausible exogenous background characteristics leading to differential treatment within any group.

${ }^{38}$ Darity and Myers (1990) suggest that reducing the supply of marriageable mates would increase the proportion of Black families headed by females. This is not necessarily inconsistent with the results presented here.
} 
However, the studies were conducted at a time when Black-male incarceration rates were much lower than the average in my sample. In an effort to reconcile the differences, the effect of the sex ratio needs not be linear. This would be consistent with finding a positive (non significant) effect among the White sample and a consistently negative effect in the Black sample. Presumably, small deviations from a unitary sex ratio could produce the kind of consequences Courtwright is describing. On the other hand, at some point, large shortages of men would inevitably lead to a decrease in fertility. ${ }^{39}$

According to Donohue and Levitt (2001), abortion availability, which should contribute to a reduction in teen births, led to a decline in crime with an 18 year lag. In simplistic terms, the argument presented here appears as the reverse, but this time with more immediate effects: in the Black community, the marginal impact of more men behind bars is now a decrease in early fertility. More research is necessary to identify whether this comes from an increase in the use of abortion, birth control methods or fewer sexual relations altogether. In particular it would be challenging to determine if those women forego early motherhood because of a simple shortage of men or because they anticipate that the father of a potential child may not stay around - in case he becomes incarcerated or leaves - all the more easily since there is an excess supply of women on the market. It goes without saying that finding a new man to support a single mother should be increasingly difficult in an environment where (free) men benefit from a rent.

\section{2. Education}

I follow the same methodology to study the impact of male incarceration rates on education at age 20 for single Black women. In Table 6, model (1), without any controls, the coefficient is

\footnotetext{
${ }^{39}$ An analysis on completed fertility seems worthy of interest but falls beyond the scope of the present study.
} 
negative and highly significant. Recall that the education attainment of Black women slightly declines during the 1980s. Regressing education on a time trend would result in a significant negative coefficient as well: this result is therefore not surprising. The coefficient is still negative but becomes insignificant when adding year effects in model (2).

As I cumulatively add state fixed effects (model 3), state-specific linear time trends (model 4) and state-specific quadratic time trends (model 5), the coefficient on male incarceration becomes respectively positive, significant at the $10 \%$ level and significant at the $5 \%$ level. Clustering standard errors by state or by state and year produce similar significant results. The magnitude of the coefficient also increases considerably over those specifications. The adjusted $\mathrm{R}^{2}$ roughly doubles when comparing model (2) and model (5) but levels off $(+10 \%)$ between model (4) and model (5). ${ }^{40}$ Given that education is measured in years, the coefficient in model (5) tells us that a $1 \%$ increase in the adult Black male incarceration rate (per adult Black male population 20-54 y/o) at age 19 is responsible for 2 to 3 extra months of education at age 20 . The same model applied to June CPS data similarly yields a significant coefficient comparable in magnitude. These findings are in line with those of Charles and Luoh (2006). ${ }^{41}$

All the results hold when considering the age range 20-21 (the sample size doubles). Also, I obtain similar results when considering a dummy variable on whether the individual has

\footnotetext{
${ }^{40}$ The point estimate is almost three times higher and still significant at the $5 \%$ level when using only two thirds of the sample, on the data before 1992 that is before the change of coding.

${ }^{41}$ I also wanted to understand how, in their study, the matching of women in their late twenties to early thirties to current male incarceration rates (corresponding to their state/ race/ age group) would produce meaningful estimates, given that those women completed their education many years earlier. Indeed, when selecting women from the years 1980, 1990 and 2000 only, I obtained highly significant results for all women up to their early thirties.
} 
completed high school - actually, the increase in education appears concentrated towards completion of high school more than college enrollment. Regressing Black education on White incarceration rates produces insignificant results. The sensitivity analysis conveys the same insights as before with the noticeable exception that now, removing the period 1997-2000 does not significantly affect the result. ${ }^{42}$

Model (6) corroborates the OLS results: the weighted estimation coefficient is significant at the $1 \%$ level. In model (7) the interaction term measuring the Black-White differential effect is insignificant because White women also increase their education in response to male incarceration, even though the coefficient in the White group, measured by the racial-specific prison rate, is insignificant. In model (9) the IV estimate supports the OLS result. The IV coefficient is significant, although at the $10 \%$ level only. The IV point estimate is actually higher than the OLS ones; again, the average incarceration rate is significantly higher in the states that contribute to the identification than in other states but the IV standard errors are too large. This lack of precision in TSLS estimation is not overly surprising given the small sample size and measurement error from the imperfect recoding of the education variable. ${ }^{43}$

I did not find an impact on Black women in their mid 20s, which suggests they are not going back to school: initial conditions, in this case at age 19, are critical for the entire human capital accumulation path. The increase in education observed just after teenage-hood may be linked

\footnotetext{
${ }^{42}$ Note that the TANF variables are here much less significant than previously. Welfare reforms, which herald a strong anti non-marital fertility component but no clear pro-education measure, should not influence educational achievement as much as teen fertility.

${ }^{43}$ When relaxing some of the constraints on the validity of IVs, and considering the age range 20-21 instead of just age 20, the IV coefficient remains constant in magnitude and becomes significant at the $5 \%$ level.
} 
with the fact that fewer of these women, as shown earlier, are mothers at that age. However, from the June CPS, I did not find conclusive evidence that non-mothers increase their education significantly more than mothers. ${ }^{44}$

Finally, education is not the only way through which young women can gain financial independence and self-reliance. Given that high male incarceration rates make these women more likely to graduate from high school, they could alternatively augment these women's laborforce participation or hours worked. In the following, I explore this hypothesis.

\section{3. Employment}

Studying the impact of Black-male incarceration on Black-female employment presents more difficulties of interpretation. White and Black females compete for the same jobs more than they compete for the same men. Also, the Black/White incarceration differential is likely to be correlated with employers' attitudes (and perhaps bias) towards Blacks in general. Another problem is that employment is a flow. The previous two outcomes were the product of irreversible or quasi-irreversible decisions: a woman is a mother by age twenty or she is not, she either graduates from high school or she does not; cases of going back to school in adult life are rare. In contrast, work status is adjustable: one can move in and out of the labor force, partly in response to current labor conditions. Incarceration rates could therefore influence employment at any age. Yet, it seems intuitive that male incarceration would become less relevant as a woman grows older. I therefore concentrate on early employment. The choice of variable is also important: labor-force participation, full-time employment, the number of hours worked in the

\footnotetext{
${ }^{44}$ The number of waves where spouse education is present (to check whether women "marry down") is too limited here (1986-1988, 1992 and 1994).
} 
preceding week, etc. Heuristically, my results are most striking when considering women 20-21 years old, an age when a lot of women start working after graduating from high school or after completing some college, yet they are robust to enlarging the age bracket.

As seen in Graph 8, young Black women have increased their labor-force participation in the 1990s (when that of young White women stagnated or declined). It therefore makes sense that when regressing full-time employment on incarceration without controls (Table 7, model 1), I find a significantly positive coefficient. When including year effects in model (2), the coefficient becomes weakly significant and then insignificant when state dummies are added (model 3). With the presence of linear and linear-quadratic state-level trends in models (4) and (5), the coefficient on employment becomes positive and significant at the $5 \%$ level. ${ }^{45}$ Clustering standard errors by state or by state / year produce a similar result which does not disappear when including education in the model. The sensitivity analysis yields findings similar to those found for fertility except that keeping high incarceration states alone is here inconclusive.

The conclusion that Black women increase their employment in response to Black-male incarceration is intuitive given the previous results. First, women without children work more than women who have children, and I have shown that male incarceration reduces Black women's early fertility. Second, educated women are more likely to be full-time employed than less educated women, and I have shown that male incarceration increases Black women's education. Given that this effect is concentrated at the high-school completion stage more so than at the college level, it is therefore logical to see an effect as early as at age 20-21.

The weighted estimation in model (6) confirms the findings in model (5) again with a higher precision. The most striking result comes from model (7). Not only do I find a significant

\footnotetext{
${ }^{45}$ This baseline result is consistent with Charles and Luoh (2006) who use the alternative variable "work for pay".
} 
differential effect of male incarceration on employment between young single Black and White females, but the coefficient measuring the impact among Whites, is significant and negative.

The magnitude of the coefficient is large: a 1\% increase in incarceration per 20-54 White male population decreases employment by 0.21 among white women in the age group 20-21. First, one should consider that the $95 \%$ confidence interval spans values as low as 0.04 , in fact not statistically different from those of the Black sample. Nevertheless, how do I explain such a finding? It has to be put in the light of the average incarceration that this sample of women experiences over 1978-1999: 0.49\%. A 1\% increase in incarceration, understood to be a change from 0.49 to $1.49 \%$, corresponds to roughly a $+300 \%$ increase from the average. Expressed as an elasticity this represents only -0.29 at the means of the data.

Several hypotheses can be advanced to explain this result. First, fertility does not seem to play a role. Indeed, from the June CPS, White women of the same age who do not have children reduce their employment by at least as much as do all White women from the March CPS sample. Second, for White women, I find that the impact of incarceration is more concentrated at the college level than at the high-school level. Therefore, some of those White women who work less because of male incarceration may do so because they choose to stay in school longer, while Black women of the same age are more likely to respond through a larger early participation in the labor force. Still, I explored the possibility that Black-male incarceration drives so many Black women into the labor market that it crowds out White-women employment. For that purpose I selected the sample to be those White women who declare being part of the labor force, whether employed or not. When regressing White female full-time employment on Black-male incarceration rates, I did not find conclusive results. However, I did find a significant effect when considering the variable 'work', =1 if the woman has worked a 
strictly positive number of hours the week before the interview, 0 otherwise (no gap in the collection). Within this sample of young White women, the negative coefficient on Black male incarceration is stronger and more precisely estimated when controlling for White male incarceration (which has a positive coefficient), bolstering the argument. This effect is driven by those women who have completed high school, which is not surprising since Black-male incarceration drives more Black women to complete high school and subsequently to apply for more qualified jobs. Conversely, the effect of Black-male incarceration on Black women seems to influence full time employment more so than labor force participation itself. I found no significant effects when estimating White male incarceration on Black women.

It is worth pointing out that those results accord with the graphical pattern of labor-force participation exposed earlier. They suggest that a significant reason for the observed increase in early Black female employment, the concomitant decline in early White female employment, and the according convergence between the two, is actually Black-male incarceration.

Finally, the IV estimation upholds the preceding results. In model (8), the instrumented Black-male incarceration coefficient shows a larger point estimate than in the OLS model, although the two are not statistically different. As before, the average incarceration rate is significantly higher in the states that contribute to the identification. I also checked that the IV procedure supports the findings for the White sample and for identifying crowding-out effects between Black and White employment.

\section{4 Marriage}

It sounds like a legitimate conjecture that by sending men to prison and thereby removing them from the marriage market, the marriage rate should fall. Incarceration could have even 
larger effects by inflicting the stigma of prison on those who come back to the marriage market after their release. Yet such a hypothesis would only hold if, absent incarceration, those men were to get married in the first place.

Using the same methodology as in the previous sections, I was unable to find a consistent and significant negative effect of Black-male incarceration on the probability of having been married. Even if for some age ranges I detected a 5\% level significant effect in the OLS model, it was never confirmed using IV. This conclusion applies to both the June and the March CPS.

The conclusion for Black females (and for White females as well when using Equation (4)), contrasts with the results presented by Charles and Luoh (2006). The discrepancy may stem from the possibility that some cohabitation conditions are listed in the U.S. Census as marriage. Another hypothesis to account for the discrepancy is the result I obtained from a regression using years 1980, 1990 and 2000 only, that is mimicking Charles and Luoh’s sample: in that case, I did find a highly significant negative impact on the likelihood to ever be married using both OLS and IV estimations. This confirms the benefit of working with more sample waves.

Wood (1990) argued that the lack of "quality men" is only marginally responsible for the decline in marriage rates in the Black community. Similarly, Myers (2000) found "little support for the theoretically plausible hypothesis that there are strong unintended impacts of imprisonment policies on family structure”. My conclusion concurs: it appears that a large fraction of those behind bars would not have become husbands had they remained free. That incarcerated Black men are only about half as likely to be married as non-institutionalized men of the same age (Western, 2004) reinforces this view. 


\section{Conclusion}

This work shows that the massive incarceration of Black males in the U.S. has perceptible effects on Black women in their teen years and early twenties. The different features of the picture that emerges from this study are consistent with one another: Black-male incarceration decreases early Black non-marital fertility, and increases Black-female education and early Black female employment. As a consequence, I found that Black-male incarceration indirectly decreases White-female labor-force participation.

The conclusion of this work might be construed as running against the traditional wisdom that an unfavorable gender ratio results in adverse consequences for females. Yet, the deduction that Black women's welfare increases would certainly misrepresents the message conveyed here: in a basic marriage-market model assuming rational agents, a shock in the supply of men such as that produced by massive incarceration should make women unambiguously worse off. ${ }^{46}$

The study of the effects of massive male incarceration on women's outcomes, a case of “tectonic economics” (Krueger, 2006), is in its infancy. For example, Johnson and Raphael (2005) advance that the higher prevalence of HIV among Black women is connected to Black male incarceration rates. Further exploration will give us a more comprehensive view of the different channels through which male incarceration affects women.

\footnotetext{
${ }^{46}$ Certainly, this simple analysis could be qualified. For instance, the large-scale confinement of working men could become a positive externality on labor market-oriented women. Alternatively, if women’s choices were previously constrained by men, for example if we believe that some women were bullied into demeaning roles, a decrease in early fertility, and an increase in education and job-market attachment could be viewed as beneficial. Still, these indirect effects would have to be extremely large to compensate for the direct decrease in welfare from choices made in the context of a crisis of gigantic proportions in the Black community.
} 


\section{Bibliography}

Allen, W. R., U. M. Jayakumar, K. A. Griffin, W. Korn and S. Hurtado, 2005. "Black Undergraduates From Bakke to Grutter,” Higher Education Research Institute, UCLA Graduate School of Education \& Information Studies publication.

Bureau of Justice Statistics “Correctional Population in the United States” series (19852001); "Prisoners in State and Federal Institutions on December 31st” series (1978-1984); and "Prisoners in year X" series (1983-2005)

Brien, M., 1997. "Racial Differences in Marriage and the Role of Marriage Markets," Journal of Human Resources 32: 741-778

Charles, K. K. and M. C. Luoh, 2006. "Male Incarceration, the Marriage Market and Female Outcomes, mimeo,” Department of Economics, University of Michigan

Courtwright D. T., 1996 “The Drug War's Perverse Toll,” Issues in Science and Technology 13(2).

CPS June 1979-2000 (not all inclusive). [machine readable data files] / conducted by the Bureau of the Census for the Bureau of labor Statistics. Washington: Bureau of the Census [producer and distributor] 1971-2004. Santa Monica, CA: Unicon Research Corporation [production and distributor of CPS utilities] 2005.

CPS March 1979-2000. [machine readable data files] / conducted by the Bureau of the Census for the Bureau of labor Statistics. Washington: Bureau of the Census [producer and distributor] 1962-2004. Santa Monica, CA: Unicon Research Corporation [production and distributor of CPS utilities] 2005.

Darity, W. A., and S. L. Myers, 1990. “Impacts of Violent Crime on Black Family Structure,” Contemporary Economic Policy, Vol. 8(4): pp. 15-29.

Dharmapala, D., N. Garoupa, J. Shepherd, 2006. "Sentencing Guidelines, TIS Legislation, and Bargaining Power,” mimeo, Emory University School of Law

Ditton, P. M., and D. J. Wilson, 1999. "Truth in Sentencing in State Prisons,” Bureau of Justice Statistics Special Report NCJ 170032

Donohue, J. J. III and S. D. Levitt, 2001. “The Impact of Legalized Abortion on Crime,” Quarterly Journal of Economics 116(2): pp. 379-420 
Garland, D., 2001. Mass Imprisonment, Social Causes and Consequences, Sage Publications Ltd

Greenberg, D. F., and V. West, 2001. "State Prison Populations and their Growth, 19711991.” Criminology 39(3): 615-53.

Hagan, J. and R. Dinovitzer, 1999. "Collateral Consequences of Imprisonment for Children, Communities and Prisoners." Crime and Justice 26:121-162.

Horton H. D., and N. Burgess, 1992. "Where are the Black Men, Regional Differences in the pool of marriageable Black males in the U.S.," National Journal of Sociology 6: 3-19.

Jacobs, D., and J. T. Carmichael, 2001. "The Politics of Punishment Across Time and Space: A Pooled Time-Series Analysis of Imprisonment Rates.” Social Forces 80 (1): 61-91.

Jaeger D. A., 1997. "Reconciling Educational Attainment Questions in the CPS and the Census” Monthly Labor Review, Vol. 120 (August): 36-40.

Johnson, R. C., and S. Raphael, 2005. "The Effects of Male Incarceration Dynamics on AIDS Infection Rates among African-American Women and Men,” Working Paper, Goldman School of Public Policy, U.C. Berkeley

Kaestner, R., S. D. Korenman and J. E. O’Neill. 2003. “Has Welfare Reform Changed Teenage Behaviors?,” Journal of Policy Analysis and Management 22(2): 225-248

Kiecolt, J. K., and M. A. Fossett, 1997. "Mate Availability, Economic Opportunity, and Marriage among Black Americans.” pp. 63-78 in Family Life in Black America, edited by R. J. Taylor. Newbury Park, CA: Sage Publications

Krueger, A., 2006. quoted on economicprincipals.com, January $15^{\text {th }} 2006$

Lane, S. D., R. H. Keefe, R. A. Rubinstein, B. A. Levandowski, M. Freedman, A. Rosenthal, D. A. Cibula, M. Czerwinski, 2004. "Marriage Promotion and Missing Men," Medical Anthropology Quarterly 18(4): 405-28.

Levitt, S. D., 1996. "The Effect of Prison Population on Crime Rates: Evidence from Prison Overcrowding Litigation,” Quarterly Journal of Economics 111: 319-352

Lichter, D. T., D. K. McLaughlin, G. Kephart and D. J. Landry, 1992. "Race and the retreat from marriage: A shortage of marriageable men?,” American Sociological Review 57: 781-799.

Lynch, J. P. and W. J. Sabol. 2003a. "Effects of incarceration on informal social control in communities," in B. Western, D. F. Weiman and M. Pattillo (eds.) The Impacts of Incarceration on Families and Communities, New York: Russell Sage Foundation. 
Lynch, J. P. and W. J. Sabol 2003b. "Assessing the Longer-run Consequences of Incarceration: Effects on Families and Employment," in Crime Control and Social Justice: the Delicate Balance, edited by D. Hawkins, S. L. Myers, and R. Stone: Greenwood Press.

Mauer, M. and M. Chesney-Lind (eds), 2002. Invisible Punishment: The Collateral Consequences of Mass Imprisonment New Press.

Meares, T. L., 2004. "Mass Incarceration: Who Pays the Price for Criminal Offending?," Criminology \& Public Policy Vol. 3 (2): 295-302.

Mincy R. B., 2006. Black Males Left Behind, Urban Institute Press

Mundy, L., 2006. "What's Really Behind the Plunge in Teen Pregnancy? It's time to look at boys' contributions,” Slate Magazine, Wednesday, May 3, 2006,

Myers, S. L. 2000 "The Unintended Impacts of Sentencing on Family Structure,” report presented at the Washington D.C.,” ASA Annual Meeting

Neal, D. 2004. "The Relationship between Marriage Market Prospects and Never-Married Motherhood,” Journal of Human Resources 39(4): 938-957.

Offner, P., and H. Holzer, 2002. "Left Behind in the Labor Market: Recent Employment Trends Among Young Black Men,” Center on Urban and Metropolitan Policy, The Brookings Institution, Survey Series (April).

Offner, P. 2003. Teenagers and welfare reform. Washington, DC: Urban Institute.

Oliver, P. E., G. Sandefur, J. Jacubowski and J. E. Yocom, 2006. "Have High Black Imprisonment Rates contributed to African American Child Poverty?” mimeo, Department of Sociology, University of Wisconsin Madison,

Sabol, W. J., K. Rosich, K. Mallik Kane, D. P. Kirk, and G. Dubin,. 2002. "The influence of TIS reforms on changes in state's prison sentencing practices and prison populations,” Urban Institute research report to the National Institute of Justice,

South, S. J. and K. M. Lloyd 1992 "Marriage Markets and Nonmarital Fertility in the United States,” Demography 29(2): 247-264.

Stemen, D., A. Rengifo and J. Wilson, 2005. "Of Fragmentation and Ferment: The Impact of State Sentencing Policies on Incarceration Rates, 1975-2002, Mimeo, Vera Institute of Justice

Thomas, A., 2006. "The Old Ball and Chain: Unlocking the Correlation between Incarceration and Marriage,” mimeo, Kennedy School, Harvard University 
Tucker, M. B. and C. Mitchell-Kernan (eds.), 1995. The decline in marriage among African Americans: Causes, consequences, and policy implications. New York: Russell Sage Foundation.

Vera Institute of Justice, 1996. "The unintended Consequences of Incarceration," Vera Institute of Justice Conference Proceedings

Waldfogel, J. 2004 "Welfare Reform and the Child Welfare System," Child and Youth Services Review 26(10): 919-939.

Western B., and S. McLanahan, 2000. "Fathers Behind Bars: The Impact of Incarceration on Family Formation," Contemporary Perspectives in Family Research 2: 307-322

Western, B., 2004. “Incarceration, Marriage, and Family Life,” Mimeo, Department of Sociology, Princeton University

Western, B., and B. Pettit, 2005. "Black-White Wage Inequality, Employment Rates, and Incarceration,” American Journal of Sociology 111(2): 553-78

Wilson, W. J., 1987. The Truly Disadvantaged: The Inner City, the Underclass, and Public Policy. Chicago: The University of Chicago Press

Wood, R., 1990. "Marriage Rates and Marriageable Men: A Test of the Wilson Hypothesis," The Journal of Human Resources 30: 163-193 

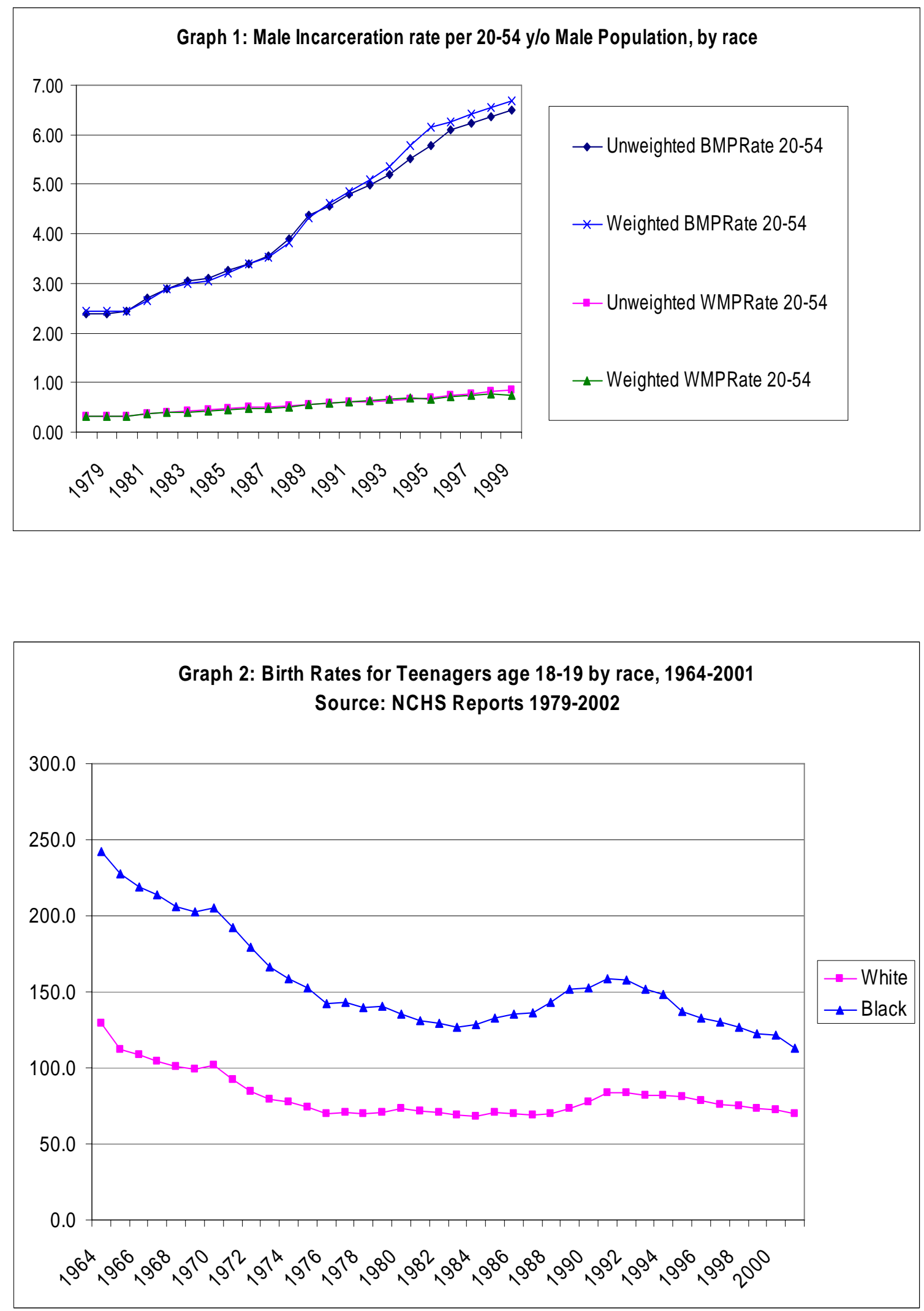

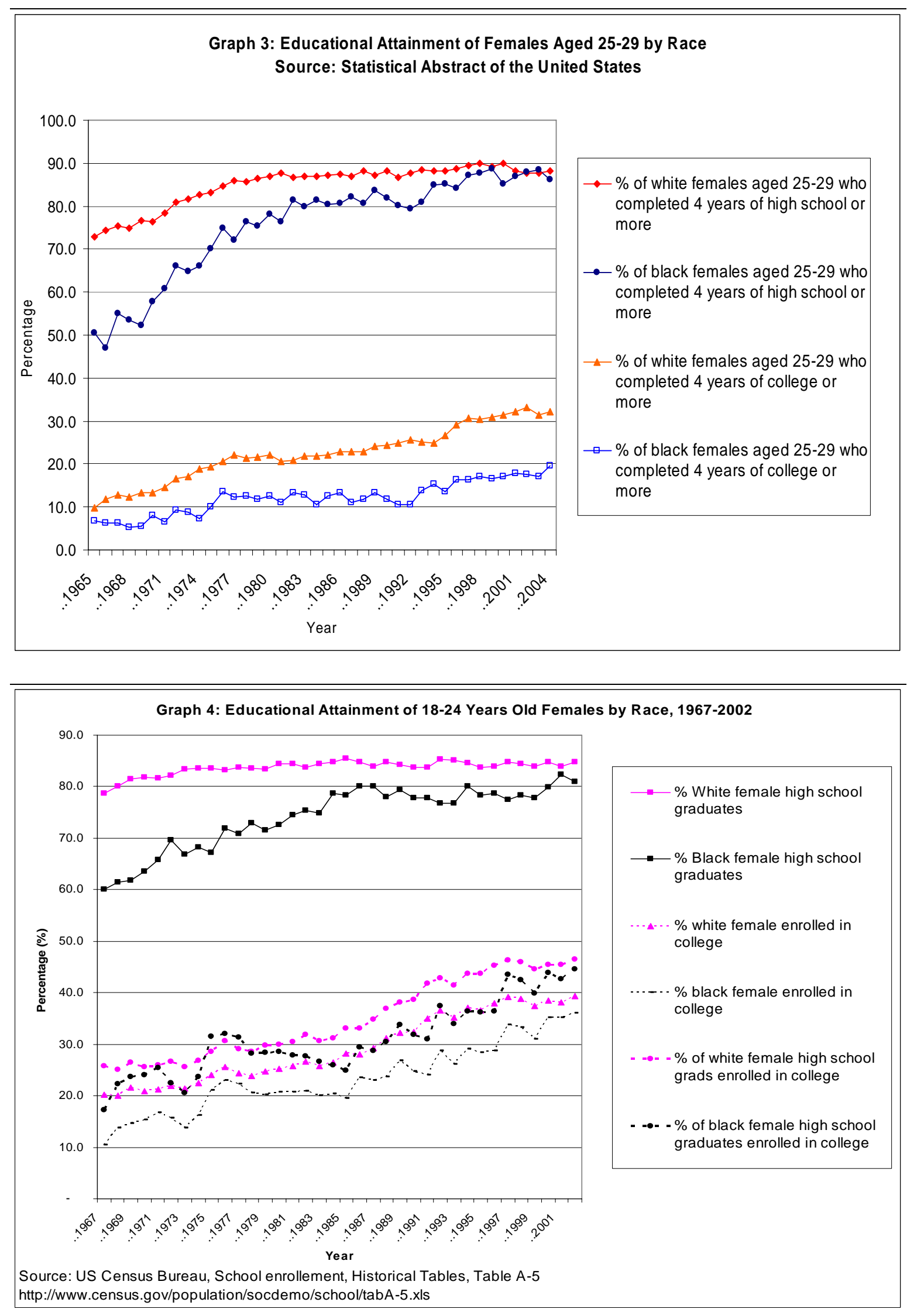

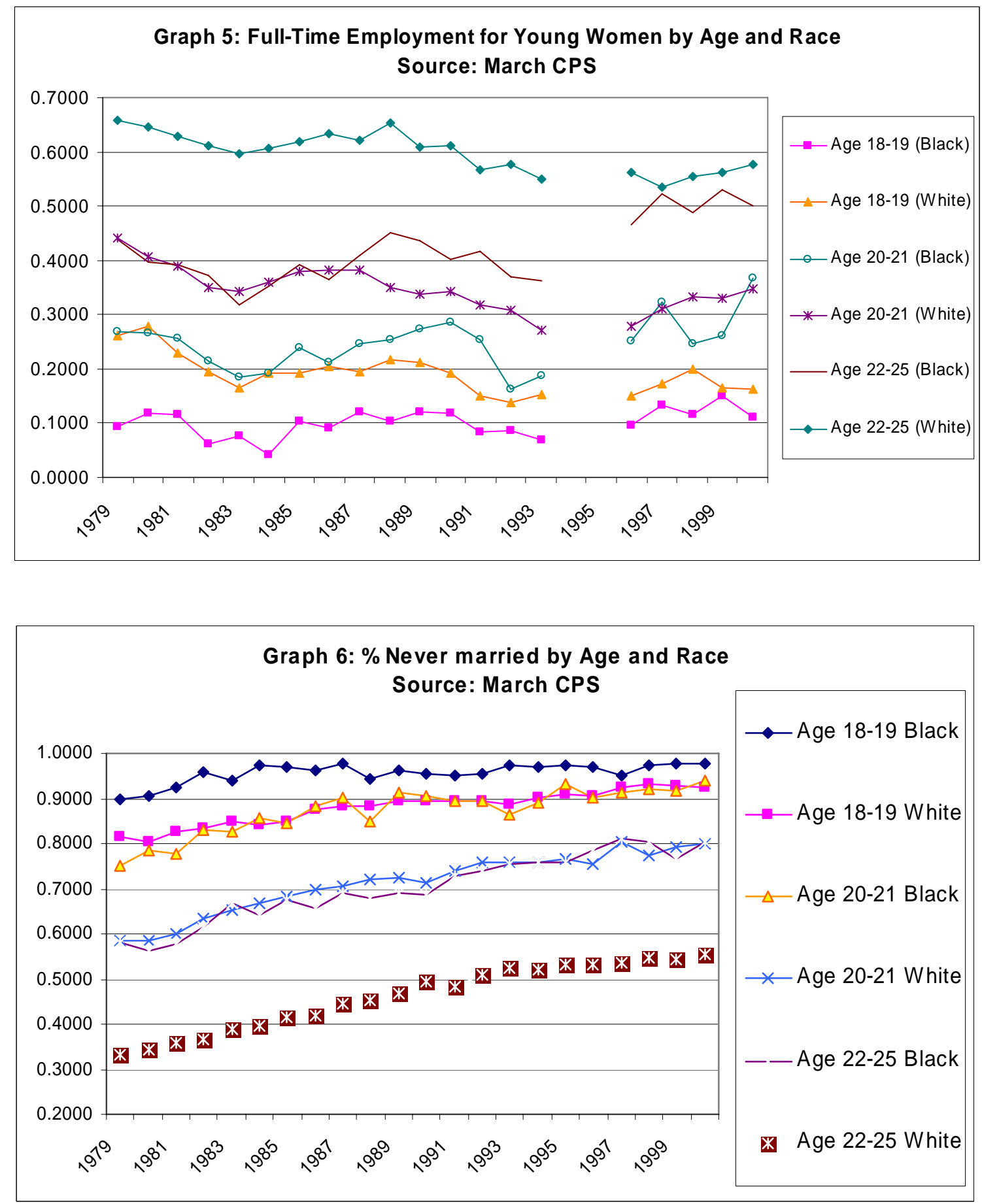


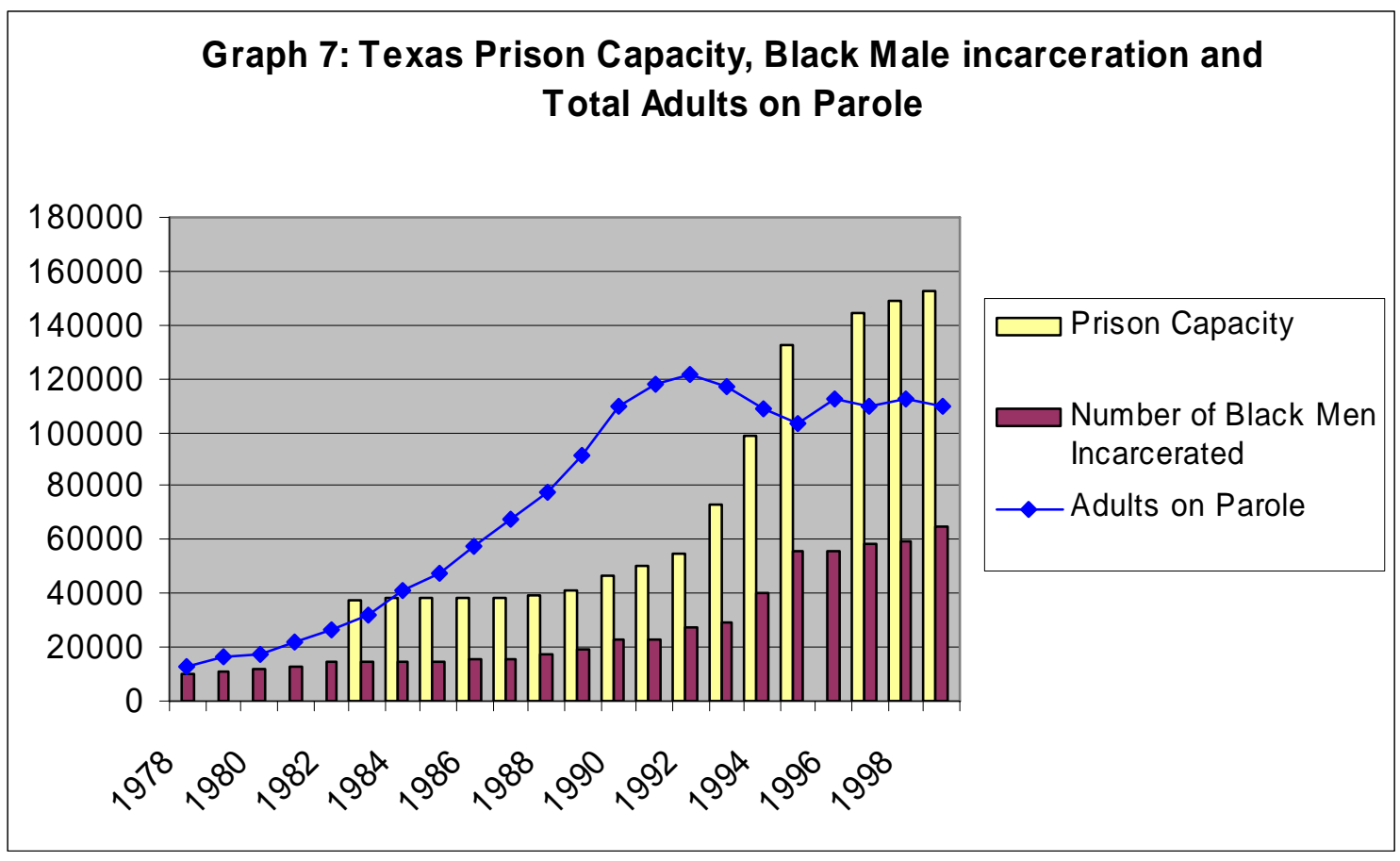


Table 1a: Black-Male Incarceration Rate per Black Male Population Age 20-54, by State, 1978-1999 (\%)

\begin{tabular}{|c|c|c|c|c|}
\hline State & Average & Std Dev & Min & Max \\
\hline Alabama & 3.9324 & 1.3456 & 1.6557 & 5.9197 \\
\hline Alaska & 4.0669 & 1.8397 & 1.6533 & 7.5946 \\
\hline Arizona & 6.2568 & 1.4773 & 3.8521 & 8.1577 \\
\hline Arkansas & 4.3687 & 1.5335 & 2.0905 & 6.3887 \\
\hline California & 4.4105 & 1.9040 & 1.6512 & 7.0943 \\
\hline Colorado & 3.8288 & 1.884 & 1.8649 & 7.0057 \\
\hline Connecticut & 6.4131 & 2.4929 & 3.093 & 11.0157 \\
\hline Delaware & 7.2035 & 2.0146 & 3.7878 & 11.1187 \\
\hline Florida & 5.2737 & 1.3872 & 3.3995 & 7.339 \\
\hline Georgia & 3.368 & 0.933 & 2.2474 & 4.8925 \\
\hline Hawaii & 1.0142 & 0.4321 & 0.1909 & 1.6237 \\
\hline Idaho & 2.4018 & 0.424 & 1.6244 & 3.095 \\
\hline Illinois & 3.9992 & 1.6056 & 1.9424 & 6.5709 \\
\hline Indiana & 4.4074 & 1.5943 & 1.7205 & 6.8409 \\
\hline Iowa & 7.0030 & 2.5029 & 3.8088 & 11.4311 \\
\hline Kansas & 5.0573 & 1.5949 & 2.6306 & 7.4548 \\
\hline Kentuckv & 4.2639 & 2.1657 & 1.7937 & 8.0479 \\
\hline Louisiana & 4.6519 & 1.7185 & 2.325 & 7.6736 \\
\hline Maine* & 1.3734 & 0.6628 & 0.69 & 2.8289 \\
\hline Marvland & 3.9019 & 0.7366 & 2.6187 & 4.7619 \\
\hline Massachusetts & 2.8651 & 0.6031 & 2.0092 & 3.7518 \\
\hline Michigan & 5.3837 & 1.8622 & 2.9974 & 7.6740 \\
\hline Minnesota & 3.5756 & 1.1151 & 2.45 & 5.3171 \\
\hline Mississidoi & 3.0907 & 1.2757 & 1.1807 & 5.7641 \\
\hline Missouri & 4.8477 & 1.9711 & 2.5407 & 8.0981 \\
\hline Montana & 2.8953 & 1.0658 & 1.4025 & 5.2686 \\
\hline Nebraska & 5.0624 & 0.7419 & 3.728 & 6.1198 \\
\hline Nevada & 6.2755 & 1.3882 & 3.4834 & 7.75 \\
\hline New Hamoshire & 2.1465 & 1.6081 & 0.3499 & 4.815 \\
\hline New Jersev & 4.1714 & 1.695 & 1.8322 & 6.6894 \\
\hline New Mexico & 3.3861 & 0.5803 & 2.4236 & 4.297 \\
\hline New York & 3.4168 & 0.9987 & 2.0899 & 4.8256 \\
\hline North Carolina & 3.4801 & 0.8818 & 2.6966 & 5.0676 \\
\hline North Dakota & 2.7345 & 1.1189 & 1.105 & 4.9025 \\
\hline Ohio & 2.8506 & 0.9838 & 1.8088 & 5.4523 \\
\hline Oklahoma & 6.453 & 2.8944 & 2.8495 & 10.691 \\
\hline Oregon & 5.1884 & 1.2313 & 2.7453 & 7.164 \\
\hline Pennsvlvania & 4.5019 & 1.9442 & 2.0034 & 7.4629 \\
\hline Rhode Island & 5.7503 & 2.2796 & 2.3331 & 9.3523 \\
\hline South Carolina & 3.8518 & 1.2056 & 2.2837 & 5.409 \\
\hline South Dakota & 2.7345 & 1.1189 & 1.105 & 4.9025 \\
\hline Tennessee & 2.8506 & 0.9838 & 1.8088 & 5.4523 \\
\hline Texas & 5.3377 & 2.7187 & 2.99 & 10.4497 \\
\hline Utah & 4.6172 & 1.1209 & 2.8921 & 6.5359 \\
\hline Vermont** & 2.5519 & 1.7884 & 0.3033 & 6 \\
\hline Virginia & 3.5871 & 1.2513 & 2.1819 & 5.4539 \\
\hline Washington & 3.738 & 0.817 & 2.711 & 5.1579 \\
\hline Washington D.C. & 7.6984 & 3.4489 & 2.5905 & 12.1901 \\
\hline West Virginia & 2.2078 & 0.7556 & 1.5277 & 3.888 \\
\hline Wisconsin & 6.2564 & 3.0144 & 3.5201 & 13.689 \\
\hline Wvoming*** & 4.1364 & 1.6078 & 1.5625 & 6.6777 \\
\hline
\end{tabular}


Table 1b: Black Male Incarceration Rate per Black Male Population Age 20-54, by Circuit Court, 1978-1999 (\%)

\begin{tabular}{|l|c|c|c|c|}
\hline Circuit Court & $\begin{array}{c}\text { Average } \\
\text { All years }\end{array}$ & $\begin{array}{c}\text { Std Dev } \\
\text { All years }\end{array}$ & $\begin{array}{c}\text { Min } \\
\text { Average }\end{array}$ & $\begin{array}{c}\text { Max } \\
\text { Average }\end{array}$ \\
\hline Circuit Court 1 & 3.053 & 2.205 & 1.4 & 4.132 \\
Circuit Court 2 & 4.477 & 2.474 & 1.834 & 7.28 \\
Circuit Court 3 & 5.292 & 2.309 & 2.587 & 8.4 \\
Circuit Court 4 & 4.121 & 2.365 & 2.387 & 5.78 \\
Circuit Court 5 & 4.36 & 2.183 & 2.2147 & 7.963 \\
Circuit Court 6 & 4.541 & 2.151 & 2.617 & 7.24 \\
Circuit Court 7 & 4.888 & 2.36 & 2.449 & 9.023 \\
Circuit Court 8 & 4.06 & 2.343 & 2.482 & 6.151 \\
Circuit Court 9 & 4.028 & 2.08 & 2.429 & 5.394 \\
Circuit Court 10 & 4.583 & 1.998 & 2.727 & 7.071 \\
Circuit Court 11 & 4.191 & 1.462 & 2.772 & 5.856 \\
\hline
\end{tabular}

Circuit Court 1: Maine, New Hampshire, Massachusetts, Rhode Island

Circuit Court 2: New York, Connecticut, Vermont

Circuit Court 3: Pennsylvania, New Jersey, Delaware

Circuit Court 4: West Virginia, Virginia, North Carolina, South Carolina, Maryland

Circuit Court 5: Texas, Louisiana, Mississippi

Circuit Court 6: Michigan, Ohio, Kentucky, Tennessee

Circuit Court 7: Wisconsin, Indiana, Illinois

Circuit Court 8: North Dakota, South Dakota, Nebraska, Minnesota, Iowa, Missouri, Arkansas

Circuit Court 9: Montana, Idaho, Washington, Oregon, Nevada, Arizona, California, Alaska, Hawaii

Circuit Court 10: Wyoming, Utah, Colorado, New Mexico, Kansas, Oklahoma

Circuit Court 11: Alabama, Georgia, Florida 
Table 2: Selected Sentencing Changes, 1975-2000

\begin{tabular}{|c|c|c|c|}
\hline State & $\begin{array}{c}\text { Truth in } \\
\text { Sentencing }\end{array}$ & $\begin{array}{l}\text { Presumptive } \\
\text { Sentencing }\end{array}$ & $\begin{array}{l}\text { Parole Restriction } \\
\text { Indicator }\end{array}$ \\
\hline \multicolumn{4}{|l|}{ Alabama } \\
\hline Alaska & & 1982 & \\
\hline Arizona & 1995 & 1979 & 1995 \\
\hline Arkansas & & & \\
\hline California & 1995 & 1977 & 1977 \\
\hline Colorado & & 1980 & 1980-85 \\
\hline Connecticut & 1996 & & $1982-90 \& 1997$ \\
\hline Delaware & 1990 & & 1991 \\
\hline Florida & 1996 & & 1984 \\
\hline Georgia & 1996 & & 1996 \\
\hline \multicolumn{4}{|l|}{ Hawaii } \\
\hline \multicolumn{4}{|l|}{ Idaho } \\
\hline Illinois & 1996 & & 1979 \\
\hline Indiana & & 1978 & 1978 \\
\hline Iowa & 1997 & & 1997 \\
\hline Kansas & 1993 & & 1994 \\
\hline Kentuckv & 1999 & & \\
\hline Louisiana & 1996 & & 1998 \\
\hline Maine & 1996 & & 1976 \\
\hline \multicolumn{4}{|l|}{ Marvland } \\
\hline \multicolumn{4}{|l|}{ Massachusetts } \\
\hline Michigan & 1995 & & 1995 \\
\hline Minnesota & 1993 & & 1981 \\
\hline Mississidni & 1996 & & 1992 \\
\hline Missouri & 1995 & & 1995 \\
\hline \multicolumn{4}{|l|}{ Montana } \\
\hline \multicolumn{4}{|l|}{ Nebraska } \\
\hline \multicolumn{4}{|l|}{ Nevada } \\
\hline \multicolumn{4}{|l|}{ New Hampshire } \\
\hline New Jersev & 1998 & 1978 & 1998 \\
\hline New Mexico & & 1978 & 1978 \\
\hline New York & 1996 & & 1999 \\
\hline North Carolina & 1994 & & 1993 \\
\hline North Dakota & 1996 & & 1996 \\
\hline Ohio & 1996 & 1997 & 1997 \\
\hline Oklahoma & 1998 & & 1999 \\
\hline Oregon & 1990 & & 1990 \\
\hline Pennsvlvania & 1911 & & \\
\hline Rhode Island & & 1982 & \\
\hline South Carolina & 1996 & & 1997 \\
\hline \multicolumn{4}{|l|}{ South Dakota } \\
\hline Tennessee & 1996 & & 1996 \\
\hline \multicolumn{4}{|l|}{ Texas } \\
\hline Utah & 1986 & & 1986 \\
\hline \multicolumn{4}{|l|}{ Vermont } \\
\hline Virginia & 1996 & & 1996 \\
\hline Washington & 1985 & & 1985 \\
\hline Washington D.C. & 1998 & & \\
\hline \multicolumn{4}{|l|}{ West Virginia } \\
\hline Wisconsin & 1999 & & 1985 \\
\hline Wvoming & & & \\
\hline
\end{tabular}

Sources: Sabol et al. (2002); Stemen et al. (2005); Ditton and Wilson (1999). 


\section{Table 3: First Stage}

Linear Regressions with robust standard errors

Samples used: Source File, Table 5 sample, Table 6 sample, Table 7 sample

Dependent Variable: "State/Year Black Male Prisoners per 20-54 Black Men (\%)”

\begin{tabular}{|c|c|c|c|c|}
\hline TIS enactment & $\begin{array}{l}(1) \\
-0.2138^{\dagger} \\
(0.1047)^{* *}\end{array}$ & $\begin{array}{l}(2) \\
-0.4008^{\dagger} \\
(0.0576)^{* * *}\end{array}$ & $\begin{array}{l}(3) \\
-0.0826^{\dagger} \\
(0.0672)\end{array}$ & $\begin{array}{l}(4) \\
-0.0708^{\dagger} \\
(0.0476)\end{array}$ \\
\hline Parole Restriction Indicator & $\begin{array}{l}-0.0993^{\dagger} \\
(0.0818)\end{array}$ & $\begin{array}{l}-0.0197^{\dagger} \\
(0.03)\end{array}$ & $\begin{array}{l}-0.1154^{\dagger} \\
(0.0454)^{* *}\end{array}$ & $\begin{array}{l}-0.075^{\dagger} \\
(0.0334)^{* *}\end{array}$ \\
\hline Presumptive Sentencing & $\begin{array}{l}-0.6438 \\
(0.2058)^{* * *}\end{array}$ & $\begin{array}{l}-0.5454 \\
(0.1088)^{* * *}\end{array}$ & $\begin{array}{l}-0.6951 \\
(0.1589)^{* * *}\end{array}$ & $\begin{array}{l}-0.8298 \\
(0.1276)^{* * *}\end{array}$ \\
\hline $\begin{array}{l}\text { California Expansion } \\
\text { (=1 } 1987 \text { on, } 0 \text { otherwise) }\end{array}$ & $\begin{array}{l}0.4749 \\
(0.1677)^{* * *}\end{array}$ & $\begin{array}{l}0.3687 \\
(0.0583)^{* * *}\end{array}$ & $\begin{array}{l}0.2812 \\
(0.0679)^{* * *}\end{array}$ & $\begin{array}{l}0.2895 \\
(0.0456)^{* * *}\end{array}$ \\
\hline $\begin{array}{l}\text { Maine Expansion } \\
\text { (=1 } 1996 \text { on, } 0 \text { otherwise) }\end{array}$ & $\begin{array}{l}1.4578 \\
(0.3123)^{* * *}\end{array}$ & - & - & - \\
\hline $\begin{array}{l}\text { Massachusetts Expansion } \\
\text { (=1 } 1995 \text { on, } 0 \text { otherwise) }\end{array}$ & $\begin{array}{l}0.3125 \\
(0.1207)^{* * *}\end{array}$ & $\begin{array}{l}0.2269 \\
(0.0653)^{* * *}\end{array}$ & $\begin{array}{l}0.2957 \\
(0.0994)^{* * *}\end{array}$ & $\begin{array}{l}0.1961 \\
(0.0598)^{* * *}\end{array}$ \\
\hline $\begin{array}{l}\text { New Hampshire Expansion } \\
\text { (=1 } 1989 \text { on, } 0 \text { otherwise) }\end{array}$ & $\begin{array}{l}1.350958 \\
(0.4138)^{* * *}\end{array}$ & - & - & - \\
\hline $\begin{array}{l}\text { North Dakota Expansion } \\
\text { (=1 } 1998 \text { on, } 0 \text { otherwise) }\end{array}$ & $\begin{array}{l}0.8531 \\
(0.2693)^{* * *}\end{array}$ & - & - & - \\
\hline $\begin{array}{l}\text { South Dakota Expansion } \\
\text { (=1 } 1996 \text { on, } 0 \text { otherwise) }\end{array}$ & $\begin{array}{l}1.016578 \\
(0.3608)^{* * *}\end{array}$ & - & - & - \\
\hline $\begin{array}{l}\text { Texas Expansion } \\
\text { (=1 } 1994 \text { on, } 0 \text { otherwise) }\end{array}$ & $\begin{array}{l}2.489204 \\
(0.778)^{* * * *}\end{array}$ & $\begin{array}{l}1.8851 \\
(0.144)^{* * * *}\end{array}$ & $\begin{array}{l}2.9494 \\
(0.3179)^{* * *}\end{array}$ & $\begin{array}{l}3.841 \\
(0.138)^{* * *}\end{array}$ \\
\hline $\begin{array}{l}\text { West Virginia Expansion } \\
\text { (=1 } 1995 \text { on, } 0 \text { otherwise) }\end{array}$ & $\begin{array}{l}1.0787 \\
(0.3098)^{* * *}\end{array}$ & $\begin{array}{l}1.7113 \\
(0.4785)^{* * *}\end{array}$ & $\begin{array}{l}0.6961 \\
(0.4045)^{*}\end{array}$ & $\begin{array}{l}1.2129 \\
(0.5571)^{* *}\end{array}$ \\
\hline $\begin{array}{l}\text { Wisconsin Expansion } \\
\text { (=1 } 1998 \text { on, } 0 \text { otherwise) }\end{array}$ & $\begin{array}{l}1.6108 \\
(0.8859)^{* * *}\end{array}$ & $\begin{array}{l}2.3406 \\
(0.5109)^{* * *}\end{array}$ & $\begin{array}{l}2.673558 \\
(0.2678)^{* * *}\end{array}$ & $\begin{array}{l}2.0165 \\
(1.2171)^{*}\end{array}$ \\
\hline Adjusted $\mathrm{R}^{2}$ & 0.9699 & 0.9777 & 0.9799 & 0.9789 \\
\hline F-test (all IV =0) & 10.11 & 51.13 & 37.75 & 121.56 \\
\hline \# Observations & 1,108 & 5,369 & 2,762 & 4,799 \\
\hline
\end{tabular}

Model (1): Source file sample; model (2): sample used in Table 5; model (3): sample used in Table 6; models (4): sample used in Table 7. Models (1)-(4) contain year, state, state $\times$ trend and state $\times$ trend $^{2}$ effects

[State] Expansion refers to a major prison capacity expansion in that state

Even though there are no observations from Maine, New Hampshire, South Dakota, North Dakota in the samples used in Table 5, 6 and 7 the coefficients are significant when enlarging samples to include older people in some of our robustness checks hence I also present them in this table.

${ }^{\dagger}$ Significant jointly at the $1 \%$ level 
Table 4: Summary Statistics of Dependent Variables

\begin{tabular}{|c|c|c|c|c|c|}
\hline & \# Observations & Average & Std Dev & Min & Max \\
\hline \multicolumn{6}{|l|}{ Table 5} \\
\hline “Whether a Mother,” (Black) & 5,369 & 0.2958 & - & 0 & 1 \\
\hline “Whether a Mother,” (White) & 28,987 & 0.0634 & - & 0 & 1 \\
\hline \multicolumn{6}{|l|}{ Table 6} \\
\hline $\begin{array}{l}\text { "Educational attainment" } \\
\text { (Black) }\end{array}$ & 2,762 & 12.422 & 1.5467 & 0 & 18 \\
\hline $\begin{array}{l}\text { "Educational attainment" } \\
\text { (White) }\end{array}$ & 14,969 & 12.9017 & 1.598 & 0 & 18 \\
\hline \multicolumn{6}{|l|}{ Table 7} \\
\hline $\begin{array}{l}\text { "Full Time Employed” } \\
\text { (Black) }\end{array}$ & 4,799 & 0.2446 & - & 0 & 1 \\
\hline $\begin{array}{l}\text { "Full Time Employed" } \\
\text { (White) }\end{array}$ & 26,110 & 0.3513 & - & 0 & 1 \\
\hline
\end{tabular}


Table 5

Linear Regressions with robust standard errors

Sample: June CPS unmarried Black women age 18-20 ${ }^{\dagger}$

(1979-85, 1990, 1992, 1994-1995, 1998, 2000)

Dependent Variable: "whether a mother”
(1)
(2)
(3)
(4)
(5)
(6)
(7)
(8) (IV)

Black Prison rate

$0.0014 \quad 0.001$

$-0.0021$

$-0.0393$

$-0.0432$

$-0.0585$

$-0.1206$

$(0.003)$

$(0.0049)$

$(0.0076)$

$(0.0149)^{* * *} \quad(0.0192)^{* *}$

$(0.0242)^{* *}$

$(0.06)^{* *}$

Prison rate

Prison rate $\times$ Black

Yes

Year

State

State $\times$ Trend

State $\times$ Trend $^{2}$

Weights

Adjusted $\mathrm{R}^{2}$
\# Observations

0.0173

0.019

5,369

5,369

$\begin{array}{ccc}\text { Yes } & \text { Yes } & \text { Yes } \\ \text { Yes } & \text { Yes } & \text { Yes } \\ & \text { Yes } & \text { Yes } \\ & & \text { Yes }\end{array}$

Yes
Yes
Yes
Yes
Yes

$$
\begin{aligned}
& (0.0467) \\
& -0.0948 \\
& (0.0504)^{*}
\end{aligned}
$$

All models control for age, age ${ }^{2}$

${ }^{\dagger}$ In model (7) using both Blacks and Whites, the prison rate is race-specific and all the controls interacted with the white dummy are added - see Equation (4). 


\section{Table 6}

Linear Regressions with robust standard errors Sample: March CPS unmarried Black women age $20^{\dagger}$

$$
\text { (1979-2000) }
$$

Dependent Variable: "Last attended grade at age 20"*

$\begin{array}{llllll}(1) & (2) & (3) & (4) & (5) & (6) \\ -0.0691 & -0.0225 & 0.023 & 0.1023 & 0.2163 & 0.2827 \\ (0.0134)^{* * *} & (0.02) & (0.0367) & (0.0606)^{*} & (0.0943)^{* *} & (0.1018)^{* * *}\end{array}$

(7)

(8) (IV)

Black Prison rate

20-54 y/o

$$
(0.0134)^{* * *} \quad(0.02) \quad(0.0367)
$$$$
(0.0606)^{*}(0.0943)^{* *}
$$$$
(0.1018)^{* * *}
$$

Prison rate

Prison rate $\times$ Black

$-0.2775$

(0.347)

Year

\section{State}

State $\times$ Trend

State $\times$ Trend $^{2}$

\begin{tabular}{|c|c|c|c|c|c|c|c|c|}
\hline Adjusted $\mathrm{R}^{2}$ & 0.0079 & 0.0121 & 0.0189 & 0.0207 & 0.0228 & 0.0083 & 0.0631 & 0.0214 \\
\hline \# Observations & 2,762 & 2,762 & 2,762 & 2,762 & 2,762 & 2,762 & 17,731 & 2,762 \\
\hline
\end{tabular}

Weights 
Table 7

Linear Regressions with robust standard errors

Sample: March CPS unmarried Black women age 20-21 ${ }^{\dagger}$

(1979-1993 and 1996-2000)

Dependent Variable: "Employed full time”

$\begin{array}{llllll}(1) & (2) & (3) & (4) & (5) & (6) \\ 0.0089 & 0.0084 & -0.0002 & 0.0321 & 0.0434 & 0.0735 \\ (0.003)^{* * *} & (0.0048)^{*} & (0.0083) & (0.015)^{* *} & (0.02)^{* *} & (0.0259)^{* * *}\end{array}$

(7)

(8) (IV)

Black Prison rate

20-54 y/o

$$
(0.003)^{* * *} \quad(0.0048)^{*}
$$

Prison rate

Prison rate $\times$ Black

State

State $\times$ Trend

State $\times$ Trend $^{2}$

Weights

Adjusted $\mathrm{R}^{2}$$$
0.0139
$$

Yes

Yes

4,799

Yes
Year

$$
\begin{aligned}
& 0.008 \\
& 4,799
\end{aligned}
$$$$
4,799
$$

\# Observations
(083)

0.1522

$(0.0565)^{* * *}$

$-0.2135$

$(0.0886)^{* *}$

0.2569

$(0.0908)^{* * *}$

$\begin{array}{lr}\text { Yes } & \text { Yes } \\ \text { Yes } & \text { Yes } \\ \text { Yes } & \text { Yes } \\ & \text { Yes }\end{array}$

Yes

Yes

Yes

Yes

Yes

Yes

Yes

Yes
Yes

Yes

Yes

Yes

Yes

Yes

Yes

0.0256
4,799

0.0323

0.0326

0.0227

0.0257

0.0263

4,799

4,799

30,909

4,799
All models control for age

${ }^{\dagger}$ In model (7) using both Blacks and Whites, the prison rate is race-specific and all the controls interacted with the white dummy are added - see Equation (4). 